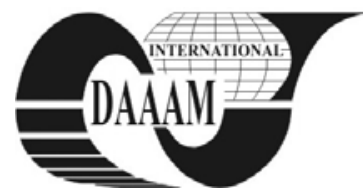

\title{
RADIOSCOPIC MEASUREMENT ON FUEL FILTER SUPPORT: INSPECTION FOR HEALTH OF MATERIAL
}

\author{
DESPOT, V[eselka]; BARISIC, B[ranimir]; KATALINIC, B[ranko]; KRSULJA, M[arko] \& CAR, Z[latan]
}

\begin{abstract}
In this paper the radioscopic measurements of a die cast product the fuel filter (C4001469SE) support is investigated. Alloy AlSi9Cu3 is investigated for porosity with $X$ - ray machine. The used measurement instrument was $X$ - ray machine YXLON CABINET 1200. An investigation of material composition was also conducted in order to detect elements that influence porosity occurrence. The measurement conditions and plan used for selected measurement procedure are discussed. The results are compared with ASTM E505 standard reference radiographs for inspection of aluminium and magnesium die casting.
\end{abstract}

Key words: radioscopy, porosity, alloy AlSi9Cu3, die-casting

\section{INTRODUCTION}

For casting procedure it is important to determine methods of control and supervision when combining different elements at elevated temperatures. The casting technology requires specific heating and cooling times. The phases of the aggregate state (solid-liquid-solid) and all the thermodynamic and physical-chemical processes make the process of casting extremely complex and depending on a lot of factors. Within the casting process different elements influence the microstructure of the final product, where they may cause imperfections in final cast product. Control of the casting process requires a constant control of input parameters and the $\mathrm{X}$ - ray machine represents only the final defect inspection evaluation.

However the material health has specific requirements and the final decision of acceptability is given by the customer specification. In this investigation tests were performed on aluminium alloy product that is used for supporting the fuel filter and the analysis of material health for 4 castings were done according to customer's demand. Standard ASTM E 505 (American Society for Testing and Materials, standard reference radiograms for inspection of aluminium and magnesium die-casting) was used for grading irregularities and materials health and according to STL S32 1156 (PSA Peugeot - Citroen Specifications Techniques Laboratories, standard for materials health). With the analysis of radioscopic X -ray shots insight into materials health was gained. Based on the results and inspection of initial chemical composition the influencing factors in the process were detected and recommendations are given for upgrading the quality of the production process.

\section{USED ALLOY AND CASTING PROCESS}

\subsection{Aluminium alloy AlSi9Cu3}

For getting proper quality assessment of the results obtained by the radioscopic measurement good knowledge of used materials and their chemical properties is required.

Alloy used for making fuel filter support is standard alloy for die casting, "nine" or AlSi9Cu3 and has following tags:

- Group: AlSi9Cu

- CODE: EN $46000 \mathrm{AC}$

- Designation: EN AC - AlSi9Cu3 (Fe)

- $\quad$ The technology of casting: GD - AlSi9Cu3 (Fe) (mark GD - die-casting, $\mathrm{K}$ - chill casting)
- Condition of the casting: GD - AlSi9Cu3 (Fe) - F - cast, $\mathrm{O}$ - without heat treatment, T6 - tempered.

IN BRIEF: tag for selected alloy and the casting of die cast without any heat treatment would be as follows: EN AC 46000 GD - AlSi9Cu3 (Fe) - FOR.

Composition tolerances for alloy elements of cast are defined by PSA Peugeot Citroen standard for aluminium and its alloys B54 1120. Chemical composition of aluminium alloy ingots used in this investigation are confirmed by the spectrometry analyzer 3460 for aluminium. (Kršulja, et al., 2010). The minimum and maximum for basic elements of the alloys were determined and have shown agreement with calibration specimen. In that investigation several elements are address as possible cause for porosity and the reason for impurities occurrence.

Beside material composition another influential parameter is the chosen method of casting, together with its significant impact on the quality of the casting itself.

\subsection{Die casting}

Die casting is a process for nearly finished manufacturing product and consists of pouring molten metal into permanent metal molds. Melt is being injected into a water-cooled mold under high pressure at high speed. During the casting process, it induces casting defects. The most common defect in aluminium die casting is porosity.

There are several types of porosity:

- $\quad$ shrinkage porosity (occurs as a result of melt shrinkage and contraction during solidification),

- $\quad$ gas porosity (occurs as a result of air entrapment during the filling of the melt tools)

- inclusion (the case of oxides due to poor cleaning of the melt but may also be inclusions of solid material)

\section{RADIOSCOPY AND USED X-RAY MACHINE YXLON 1200}

$\mathrm{X}$-ray imaging techniques, i.e. the non-destructive testing and evaluation (NDT\&E) techniques, such as radioscopy are used for increasingly diverse applications in the manufacturing industry (defect inspection system evaluation).

Penetrating radiation originating in the disintegration of radioactive preparations and the emission from the anode of an $\mathrm{X}$-ray tube is used in quality inspection of metal products such as casts. The phenomenon of diversification of this radiation absorption was used in our investigation. The degree of X-ray radiation weakening is also connected with the density of examined materials. In this way the participation of so-called micro-porosity in a cast can be monitored. Depending on the thickness of the investigated material different power is used for imaging penetration purposes. Standard examinations allow detecting fractures of casts and macro-discontinuities like gas cavities, as well as discontinuities connected with contraction phenomena occurring during metal solidification (shrinkage cavity) (Gawdziñska, et al, 2008).

Investigation of selected product cast Alloy AlSi9Cu3 was done by radioscopic measurement in the foundry CIMOS in 
Roč with X-ray machine "YXLON 1200". Used X-ray machine has the following characteristics:

- Max. current $6 \mathrm{~mA}$,

- Max. source voltage $160 \mathrm{kV}$,

- Max. ability to carry the sample weight is up to $10 \mathrm{~kg}$, size $30 \times 30 \mathrm{~mm}$

- The possibility of rotation of the sample and move up down, left - right and forward - backward, in order to obtain full insight into porosity occurrence.

Software PXV2200/PXV2200R was used for actual measurement. It is a PC based system for image enhancement and storage specifically designed for radioscopic inspection.

\section{STANDARD FOR HEALTH OF MATERIALS AND ASTM E505}

Standard for health of materials aims to define the level of acceptability to be fulfilled by casting in the matter of health of material and defects on machined surfaces. Standards for health of materials used on fuel filter support is STL S32 1156. Defined zone (shown in following figure) represents areas that perform the mechanical function and must be tested. Any part that is not defined as zone 1 is called "routine" zone (area 2 or in our case the rest area)

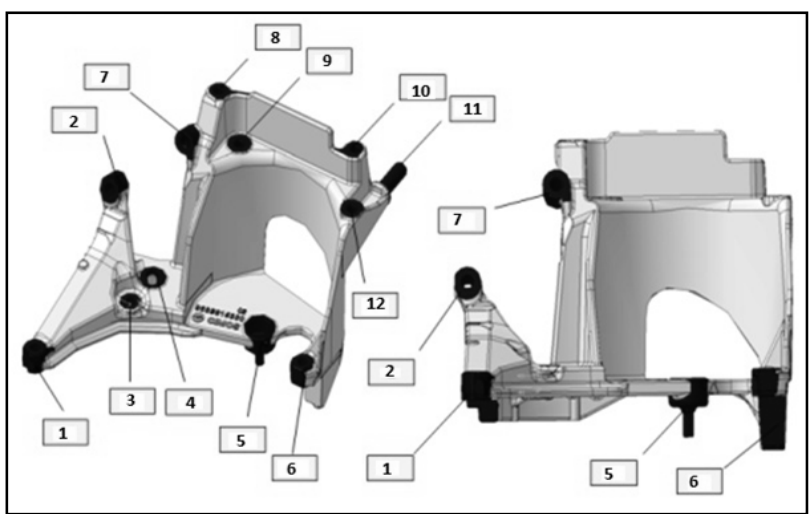

Fig. 1 . The scheme of fuel filter support with marked areas, 12 test points (zone 1)

Before starting with radioscopic examination the position of shooting plan must be determined. For the concrete test sample 8 frames will be recorded. Standard ASTM E505 is taken into consideration for the materials health control.

\begin{tabular}{|c|c|c|}
\hline $\begin{array}{c}\text { The marked area } \\
-1\end{array}$ & \multicolumn{2}{|c|}{ ASTM E 505 } \\
\cline { 1 - 2 } Other area -2 & Zone 1 & Zone 2 \\
\hline $\begin{array}{c}\text { type of } \\
\text { irregularity }\end{array}$ & 2 & 2 \\
\hline Shrinkage & 1 & 2 \\
\hline Porosity & 0 & 1 \\
\hline Cold fill & 0 &
\end{tabular}

Tab. 1. Requirements for the control of health of casting according to ASTM E 505

\section{RESULTS}

The positions, which are defined in the plan of shooting positions, are recorded using the radioscopic X-ray systems. In our case, according to customers' requirement the test is performed on 4 samples. Obtained radioscopic images are compared to every type of indication from the selected reference images from the standard (ASTM E505). Rating radioscopic pictures is performed in a darkened room on a monitor. Report on radioscopic test of aluminium casting is made after examination and its study aims to show the level of acceptability regarding standard for health of materials. The document indicates the actual state of test samples and allowed metallurgical irregularities in the samples.
On the four samples we examined, only shrinkage cavity was found but all irregularities were in the level of acceptability according to STL S32 1156 standard for health of materials.

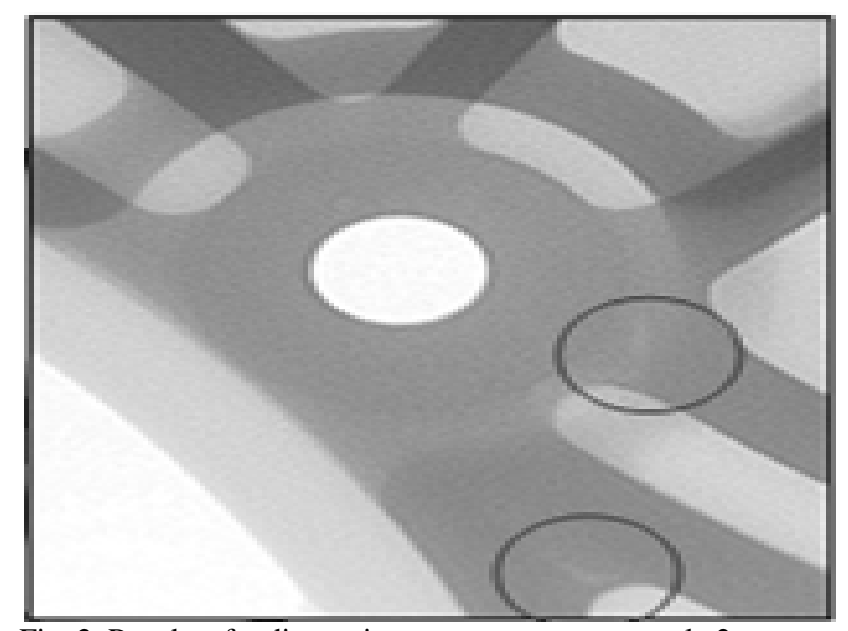

Fig. 2. Results of radioscopic measurements on sample 2, porosity has been detected

\section{CONCLUSION}

All four samples tested meet customers' requirement. Input material was according the standard and process parameters were conducted accordingly. Radioscopy detected some irregularities that need to be addressed, however the standard requirements were met. The porosity occurrence can be traced to slight changes in material composition and heating and cooling times of production as they represent the biggest influence on porosity occurrence.

The quality of radioscopic examination depends as much on what technology has to offer in terms of detectors and system design as it does on the training level of the inspectors and their professional qualification.

Further research will be focused on examination of more complicated samples together with research of any detected porosity even if the cast is within the standard parameters.

\section{ACKNOWLEDGEMENTS}

The authors would like to acknowledge the support provided by the National CEEPUS Office of Croatia and National CEEPUS Office Austria, which helped the research through mobility in the frame of the CEEPUS II HR 0108 project.

\section{REFERENCES}

Gawdziñska K.; Grabian J, Przetakiewicz W., Use of X-Ray radiography in finding defects in metal-matrix composite casts, Metalurgija, vol 47 (2008), 3, 199-201, ISSN 05435846

Kakas D.; Kovacevic L., Terek P., Krumes D., Kolumbic Z. (2009). Use of SEM and EDS analysis in the investigation of Al-Si-Cu piston alloy cast porosity Metalurgija, vol 48 (2009), 3, 171-174, ISSN 0543-5846

Kršulja M.; Barišić B.; Plančak M.; Čep R. (2010). Investigation of alluminium alloy composition AlSi9Cu3 alloy in foundury process, Technological Engineering. vol. 7 (2010), 2; 53-56. ISSN 1336-5967

Purschke M.; Gutierrez E. N. (2002). Radioscopy-The Prevalent Inspection Technique of the Future!?, Available from:http://www.aaende.org.ar/sitio/biblioteca/material/PD F/COTE249.PDF Accessed: 2011.06.29

Vinarcik Edward J. (2003). High integrity die casting process, John Wiley \& Son, ISBN 0-471-20131-6, New York

*** Internal script from Citroen Charlleville (1988). Metallurgy of aluminum and its alloys 